\title{
Leading One Another Across Time and Space: Exploring Shared Leadership Functions in Virtual Teams
}

\section{Dirigiendo Uno a Otro en el Tiempo y el Espacio: Explorando las Funciones del Liderazgo Compartido en Equipos Virtuales}

\author{
Marissa L. Shuffler, Christopher W. Wiese, Eduardo Salas and C. Shawn Burke \\ University of Central Florida
}

\begin{abstract}
Although a tremendous amount of research in the last decade has begun to disentangle interaction factors and performance outcomes associated with virtual teams, significant gaps still exist in our understanding, particularly in terms of virtual team leadership. Shared leadership may be particularly important to virtual teams, where team members' separation from the leader and from one another may necessitate the distribution of leadership functions. While the sharing of leadership has proven to be advantageous to more traditional forms of vertical leadership, there is a dearth of research concerning how shared leadership operates in, and is influenced by, virtual and distributed environments. Therefore, the goal of the current paper is to provide a framework for doing just this, primarily through presenting propositions and future research needs regarding specific leader functions that may be shared by members of virtual and distributed teams.
\end{abstract}

Key words: Shared leadership, team performance, virtual teams, distributed teams.

\begin{abstract}
Resumen. Aunque una gran cantidad de investigación en la última década ha comenzado a distinguir los factores de interacción y los resultados de rendimiento asociados con los equipos virtuales, aún existen importantes lagunas en nuestro conocimiento, sobre todo en términos de liderazgo de un equipo virtual. El liderazgo compartido puede ser particularmente importante para los equipos virtuales, donde la separación entre el líder y los miembros del equipo y entre ellos mismos puede exigir la distribución de las funciones de liderazgo. Si bien compartir el liderazgo ha demostrado ser ventajoso sobre las formas más tradicionales de liderazgo vertical, hay una escasez de investigación relativa a como opera y está influido el liderazgo en forma compartida en entornos virtuales y distribuidos. Por tanto, el objetivo de este artículo es proporcionar un marco para llevar a cabo dicha investigación, principalmente a través de la presentación de proposiciones y necesidades futuras de investigación con respecto a las funciones específicas del líder que pueden ser compartidas por los miembros de los equipos virtuales y distribuidos.

Palabras clave: Liderazgo compartido, rendimiento de equipos, equipos virtuales, equipos distribuidos.
\end{abstract}

\section{Introduction}

In 1999, the Mars Climate Orbiter satellite was lost when Lockheed Martin engineers used English measurement units against the specification from NASA, which called for metric units, causing the orbiter to attempt to enter orbit at a distance three times closer than that for which it was designed (Mars Climate Orbiter, 1999). This resulted in unanticipated forces acting against the entry and the ultimate destruction of the craft. Were the teams of engineers for NASA and Lockheed Martin collocated it would have been less likely that such a drastic error would occur.

This $\$ 125$ million disaster illustrates one of the

This research was made possible by partial funding from the National Science Foundation (0943208) and the Army Research Institute for the Social and Behavioral Sciences (W91WAW08C0028). Correspondence should be sent to Eduardo Salas, Department of Psychology, and Institute for Simulation \& Training, University of Central Florida, 3100 Technology Parkway, Orlando, Fl 32826. Email: esalas@ist.ucf.edu many ways distribution and virtuality can lead to difficulties in team interaction, especially when leadership responsibilities are shared among team members. Although a tremendous amount of research in the last decade has begun to disentangle interaction factors and performance outcomes associated with virtual teams (Burke, Lum, Scielzo, Smith-Jentsch, \& Salas, 2009; Duarte \& Snyder, 2006; Fiore, Salas, Cuevas, \& Bowers, 2003; Hertel, Geister, \& Konradt, 2005; Lyons, Priest, Wildman, Salas, \& Carnegie, 2009), significant gaps still exist in our understanding. This lack of understanding is particularly problematic given that organizations of all types have increasingly turned to team-based work structures to solve complex problems and generally improve performance (Salas, Kosarzycki, Tannenbaum, \& Carnegie, 2005).

One aspect of teams that is often explored in virtual teams is their leadership (Avolio \& Kahai, 2003; Yoo $\&$ Alvari, 2004). Due to increased complexity in ensuring effective team processes when faced with virtual and distributed team environments, leadership behav- 
iors may often be shared among members. Shared leadership has been defined multiple ways, but across researchers there appears to be a unified agreement that shared leadership involves team members distributing leadership responsibilities amongst themselves, without negating the possibility of vertical leadership (Pearce \& Conger, 2003). As with the broader leadership literature there have been a variety of leadership behaviors and/or functions which have been argued to be the content of shared leadership (Morgeson, DeRue, $\&$ Karam, 2009). Many researchers have looked at the components that predict the success of these shared leadership behaviors and the impact it has in a variety of environments (Carson, Tesluk, \& Marrone, 2007; Merkens \& Spencer, 1998).

Shared leadership may be particularly important to virtual teams, where team members' separation from the leader and from one another may necessitate the distribution of leadership functions. While the sharing of leadership has proven to be advantageous to more traditional forms of vertical leadership (Pearce, Yoo, \& Alvai, 2004), there is a dearth of research concerning how shared leadership operates in, and is influenced by, virtual and distributed environments. Therefore, the goal of the current paper is to provide a framework for doing just this, primarily through examining specific leader functions that may be shared by members of virtual and distributed teams.

First, we provide a review of recent perspectives on shared leadership, virtuality, and distribution, in terms of how they have been defined and the limited research available regarding their interactions. Next, drawing upon current shared and functional leadership research, as well as what is known regarding virtual and distributed team processes and performance, we present a set of propositions regarding specific leader functions whose sharedness may be differentially impacted by the degree of virtuality and distribution within a team. Furthermore, we present propositions regarding factors that may aid in reducing any hindrances in shared leader behaviors brought about by virtuality and distribution. Finally, we highlight future research directions regarding shared leadership in virtual and distributed teams. It is hoped that by doing so, we will bring attention to an area in great need of research and future exploration, from both a theoretical and a practical standpoint.

\section{Defining Shared Leadership in VTs}

There is general agreement that leadership can substantially impact team outcomes (e.g., Bass 1990; House, 1977; Yukl, 1998), yet team researchers have been criticized for their lack of attention to team leadership (Komaki, Desselles, \& Bowman, 1989; Marks \& Zaccaro, 1997). As such, research on shared leadership is in its infancy, particularly in terms of VTs. One issue with this research is the lack of agreement on the definition of shared leadership, with some considering it a process (e.g., Pearce \& Sims, 2000) and others conceptualizing it as a management strategy (Jackson, 2000). Furthermore, there is also a lack of clarification as to what is meant by virtuality and distribution as well. Research on what are often referred to as "virtual teams" is vast; yet much of the literature claims that we do not fully understand how they function and how to lead them (e.g., Bell \& Kozlowski, 2002; Hertel et al., 2005; Morris, 2008). In fact, there is a generally pervasive belief that virtuality and geographic distribution are always hindrances to teamwork and collaboration, yet research findings provide conflicting evidence for this contention (see Connaughton \& Shuffler, 2007; Gibson \& Gibbs, 2006; Martins, Gilson, \& Maynard, 2004). The following section provides an overview of the literature surrounding each of these three terms, in order to clarify the definition of each construct that will be used for the purposes of this paper, and to aid in construct clarification.

\section{Shared Leadership}

The notion of team members sharing leadership functions is not a novel one (Ber-kowitz; 1953; Gibb, 1954; Robbins, 1952; Tannenbaum \& Massarik, 1957). However, there has been a recent revitalization of the topic. Though the research on vertical leadership is thorough and extensive, it would be naïve to suggest that leadership only functions in a vertical capacity. A recent review of the leadership literature proposes four sources of leadership, broken down into two structural dimensions: locus of leadership (internal vs. external) and formality of leadership (informal vs. formal). In this review, Morgeson, DeRue, and Karam (2009) describe an external leader as one that is not involved in day-to-day tasks, while an internal leader is seen as an equal within the group. A formal leader is directly assigned to be a leader (e.g., immediate supervisor, project lead, and the like), while an informal leader is described more as an advisor, someone that does not come into the leadership position by direct assignment. These classifications permit four sources of leadership, with vertical leadership being classified as externalformal and shared leadership falling under the internalinformal source. Given the different sources of leadership, it is impossible for any individual to hold the requisite knowledge and skill to provide leadership from all of these sources simultaneously. Therefore, the study of all of these sources, not just external-formal, is integral to the success of the organization.

Additionally, the sharing of leadership has emerged as a critical component in the modern organizational world. The ever-changing environmental conditions of the organization make the sharing of leadership critical for survival (Merkens \& Spencer, 1998). Moreover, 
those who are doing the job best understand the complexity of the modern organizational setting and, consequently, those individuals are often the best to improve the job (Jackson, 2000). Ultimately, research has suggested that shared leadership is most effective when tasks are interdependent and complex (Pearce, 2004).

Shared leadership has been conceptualized in many ways (Carson, Tesluk, \& Marrone, 2007; Friedrich, et al. 2009), but the underlying theme among these definitions is that shared leadership involves the distribution of the leadership responsibilities within the team (see Jackson, 2000; Lambert, 2002; Pearce \& Conger, 2003), while not negating the possibility of vertical leadership. The different conceptualizations of shared leadership differ on what constitutes leadership and the manner in which responsibilities are shared. For example, there is a stream of leadership research that explicitly views shared leadership as an emergent state (Day, Gronn, \& Salas, 2004 - leadership capacity), while another stream of research does not reject the possibility that shared leadership could be formally prescribed (Pearce \& Sims, 2002). Much like the broader leadership literature, shared leadership has been thought to consist of a variety of leadership behaviors and/or functions. The next section will detail a couple of the more prominent models and/or frameworks in the shared leadership literature. This will allow further elaboration on the behaviors said to be the content of shared leadership.

When breaking down and examining the nomological net surrounding shared leadership, researchers have put forth several theoretical models and frameworks in hopes to best explain the shared leadership phenomenon. Pearce and colleagues have put forth a stream of research investigating shared leadership. Perry, Pearce, and Sims (1999) developed a model of shared leadership within the context of empowered selling teams. They identified transactional, transformational, directive, empowering, and supportive behaviors as being tied to shared leadership. Further, this model proposed that when teams engage in these behaviors, critical affective (e.g., commitment, satisfaction, potency, cohesiveness), cognitive, and behavioral (e.g., effort, communication, citizenship behavior) outcomes result. These outcomes result in qualitative and quantitative markers for team effectiveness. Additionally, Ensley, Pearson, and Pearce examined top management teams when developing a model that examined the influence of shared leadership on promoting key affective and behavioral components related to team effectiveness, as well as identifying moderating variables of this relationship. Specifically, this model postulates that shared leadership is related to the development of cohesion and shared vision, which, in turn, is related to team effectiveness. They identified possible contextual moderating variables (e.g., time, resource constraints, risk, and ambiguity) that impact the shared leadershipcohesion/shared vision relationships.
Other research has put forth several competencies that are said to foster shared leadership. For example, Lambert (2002) suggests the ability to: negotiate winwin solutions through team learning, influence follower behavior, problem solve within a systems framework, and use shared visioning to empower members. Additionally, an examination of the role theory literature by Carson and Tesluk (2007) produced four roles (e.g., navigator, engineer, social integrator, and liaison) which yielded utility to team members without formal title or position of authority, as is often the case with shared leadership. When these roles manifest within a team there appears to be a clear team direction and purpose (navigator), structuring of team roles, functions, and responsibilities (engineer), development and maintenance of team coherence (social integrator), and development of relationships with key external stakeholders (liaison). In an examination of these roles within 42 MBA consulting teams, Carson and Tesluk (2007) found that shared leadership (conceptualized as the above behaviors) was positively related to performance. However, contrary to expectations, the role differentiation, with respect to these behaviors, was negatively related to shared leadership. One explanation of this result suggested by the researchers is that shared leadership is not a concrete pattern of highly differentiated roles, but that team members adapt and exercise more than one of these roles within a given performance episode, based on dynamic situational demands.

Besides work on the models and frameworks of shared leadership, research has delineated some conditions which may impact the emergence of shared leadership. For example, Pearce, Perry, and Sims (2001) identify five conditions: geographic dispersion, demographic heterogeneity, team size, skill heterogeneity, and maturity. Geographic dispersion, large team size, and demographic heterogeneity are expected to negatively impact the likelihood of shared leadership emerging as coordination and communication. Conversely, skill heterogeneity should facilitate the emergence of shared leadership as different skills are often needed based on the temporal point in the team's life cycle. Teams with breadth in their abilities are more likely to be positioned to effectively engage in shared leadership, given the right climate and that members are comfortable with and cognizant of the possession of different skills.

As stated in the beginning of this section, the emergence of shared leadership does not negate the possibility of vertical leadership. Vertical leadership has been hypothesized to play a key role in creating the conditions necessary for the emergence of shared leadership. For example, Perry et al., (1999) suggest that both vertical leadership and team characteristics (i.e., ability, proximity, maturity, diversity, and size) are important in creating the conditions which foster the emergence of shared leadership. They suggest that the vertical leader is responsible for the generation of a 
team design that fosters the emergence of shared leadership, places and manages appropriate boundary conditions, and enacts facilitative and contingent leadership behaviors. Pearce (2004) extends the research on conditions that facilitate shared leadership by suggesting that, in addition to vertical leadership, the organizational context can facilitate the emergence of shared leadership. Specifically, organizations need to enact training, development, and reward systems that encourage and rewards shared leadership behaviors.

Although research has begun to investigate the recent conceptualizations of shared leadership with regards to performance, there is still much to be done. So far, the majority of the research investigating shared leadership has focused on its underlying components or its relation to performance. These underlying components are typically conceptualized as transactional, transformational, aversive, directive, and empowering behaviors, results from which have indicated that shared leadership not only has a positive relationship with job performance across a number of domains (e.g., selling teams, consulting teams, top management teams, entrepreneurial teams), but also accounts for more variance in performance than traditional vertical leadership (Ensley, Hmieleski, \& Pearce, 2006; Pearce et al., 2004; Pearce \& Sims, 2002). Additionally, some studies have also investigated multiple shared leadership roles (i.e., Carson, Tesluk \& Marrone, 2007; Tesluk; Yang \& Shao, 1996); however, the ambiguous conclusion from this line of research leads to more questions that have yet to be answered.

This focus on performance has lead to a dearth of research investigating shared leadership's relation to process or emergent states. Only a few studies have investigated shared leadership in this capacity. These studies have found that teams engaging in shared leadership have been found to engage in greater amounts of collaboration, coordination, and cooperation (Manz \& Sims, 1993; Yeatts \& Hyten, 1998). There has also been some initial undertaking in investigating the relationship between culture and shared leadership. Hiller et al., (2006) found shared leadership was positively related to collectivism, but not related to power distance.

\section{Virtual Teams (VTs)}

Due to advances in technology and the globalization of organizations, teams may often be distributed geographically, making use of virtuality in order to accomplish tasks (Kirkman \& Mathieu, 2005). Virtuality and distribution have become focal issues in a large part of group and teams research. While originally virtuality and distribution were often viewed as dichotomies (i.e., virtual or not, fully distributed or face to face), more recently researchers have come to view them as continua (Bell \& Kozlowski, 2002; Hackman \& Katz,
2009). Virtual teams may range dramatically in terms of the degree to which they utilize virtuality, with some only communicating using highly virtual tools such as instant messaging and teleconferencing, while others are less virtual, making use of videoconferencing and regularly scheduled face to face meetings. Similarly, teams can range in their degree of distribution, with some teams having all members fully distributed in separate locations or, more commonly, teams with some degree of partial distribution, such as the leader, in the same location as two or three team members and the remaining team members spread out in various locations. While much has been done to advance our understanding of virtuality and distribution's impacts on team processes and performance, capturing the nuances of these differing degrees of virtuality and distribution remains challenging for researchers (Connaughton \& Shuffler, 2007; Gibson \& Gibbs, 2006). In the following we provide further detail regarding how virtuality and distribution are viewed for the purposes of this paper.

Virtuality. One of the defining characteristics of a virtual team is the computationally enabled and enhanced nature of its communication (Cummings \& Kiesler, 2008). Within such teams, technologically mediated tools are necessary for communication to occur, as its members may be separated by space and time and therefore are unable to meet face to face on a regular basis (Jarvenpaa \& Leidner, 1999). It is also believed that the complex nature of the tasks completed by virtual teams require advanced tools with rich informational value in order to effectively share ideas.

While the use of such tools is becoming commonplace throughout teams and organizations, consistent empirical research regarding their differential impact on team processes and performance is lacking (Connaughton \& Shuffler, 2007). Multiple theories exist to explain the differences in media and why some may be more or less effective, including media richness (Daft \& Lengel, 1986) and media naturalness (Kock, 2002; 2004; 2005). For example, media richness theory places different forms of communication on a continuum, with face to face interaction being the richest media, providing the most contextual cues and information, and letters or other paper based media as the least rich due to their lack of social cues. Media naturalness builds upon this theory, identifying multiple components of technologies that make them more or less natural. According to media naturalness theory, as technologies become less natural (i.e., more aspects of human face to face interaction are suppressed), the task of interaction becomes more cognitively effortful, the ambiguity of the communication increases, and the level of physiological arousal decreases.

While these theories aid in our understanding as to why media may elicit differential effects, most empirical studies of virtual teams and organizations examine a limited set of virtual tools (e.g., email, chat systems) 
that are simply classified as either virtual or not (Kirkman \& Mathieu, 2005). As these tools can potentially differ in their degree of virtuality, such a dichotomous classification system stifles a rich, meaningful understanding of the degree to which these tools vary in their effectiveness and the degree to which they facilitate or hinder the collaborative processes vital to team and organizational performance.

To more precisely address the factors of virtuality that determine the richness and naturalness of a tool, Kirkman and Mathieu (2005) delineated three dimensions that comprise virtuality: 1) the extent of reliance on virtual tools, 2) informational value, and 3) synchronicity offered by such tools. The extent of reliance on virtual tools describes the proportion of team interaction that occurs via virtual means. One on end of this continuum, some teams are completely face-to-face in terms of interacting and use no virtual tools whatsoever. Meanwhile, on the other end are teams that interact solely through virtual means. Teams can fall anywhere along this continuum, for example, having a face-toface kickoff meeting but interacting for a majority of the time using virtual tools such as teleconferencing and email, or vice versa. Informational value is the extent to which virtual tools transmit data that is valuable for team effectiveness. Kirkman and Mathieu argue that, when technologies convey rich, valuable information, exchanges are less virtual than when compared to exchanges via technologies that provide less rich information. Synchronicity is the extent to which team interactions occur in real time or incur a time lag. These three dimensions combine to determine a team's overall level of virtuality. For the purposes of this paper, we utilize this perspective of virtuality.

Distribution. Another defining characteristic of teams and organizations is the physical distribution of team members across space (Cummings, et al., 2008). Team members may be fully distributed, with all members located in different geographical regions, or they may be partially distributed, with some team members collocated and others in one or more geographical regions, or they may be completely collocated (Bell \& Kozlowski, 2002). While it is a common assumption that team members who are distributed must be spread across large distances, full distribution can also occur for teams with members located a very short distance from one another, even within the same city or organization. Team member distribution is an important component of virtuality as it can determine what types, and how often, virtual tools are utilized, driving the degree of team virtuality.

While team member distribution has been commonly studied in virtual teams, much like the degree of virtuality, it is often dichotomized into fully distributed vs. fully collocated (i.e., face to face) teams. This distinction is problematic, as real world virtual teams typically are partially distributed, with groups of team members located in different geographical regions, utilizing technology to complete tasks together (Goodwin $\&$ Halpin, 2006). This is especially true for complex tasks that demand high levels of expertise, where individuals and teams of experts from different universities and/or businesses are brought together to work on such projects.

Unfortunately, this dichotomization of distribution has led to little empirical research regarding the impact of partial distribution on virtual teams, specifically in terms of team processes and performance. Though it has been shown that full distribution can have constraining effects on collaboration and its relevant affective, behavioral, and cognitive components, such as trust (e.g., Jarvenpaa \& Leidner, 1999), information exchange (e.g., Cramton, 2001), and communication (e.g., Cogburn \& Levinson, 2003), few studies compare full distribution to partial teams in order to understand the differential impacts of the degree of distribution. Of those that do, most have found that the balance of distribution matters significantly in terms of team outcomes (see Bos et al., 2006; Huang \& Ocker, 2006; Lawrence et al., 2007; Ocker et al., 2009; O’Leary \& Mortenson, 2005; Polzer et al., 2006). However, this research has yet to be fully combined with issues of virtuality and shared leadership. Therefore, more clarification is needed regarding when distribution may challenge or benefit team processes and performance, especially in conjunction with differing degrees of virtuality.

\section{Shared Leadership in VTs}

Certainly, leadership is an important component of VTs, as evidenced by field and laboratory studies (Hambley, et al., 2007; Hertel, Geister, \& Konradt, 2005; Webster \& Wong, 2003). However, despite the widespread research regarding leadership of VTs, few studies have examined the role of shared leadership in VT processes and performance (Wassenaar, Pearce, Hoch, \& Wegge, 2010). Much of the literature in this area is purely theoretical (e.g., Bell \& Kozlowski, 2002; Pearce Zigurs, 2003; Cascio \& Shurygailo, 2003), however, we do have some insight through empirical research.

An extensive review of the literature has revealed a limited set of empirical research that provides a starting point for exploring shared leader functions in VTs. Several researchers have looked at the components that predict shared leadership and the impact it has in a variety of environments (Carson, Tesluk, \& Marrone, 2007; Merkens \& Spencer, 1998). Shared leadership may be particularly important to virtual teams, where team members' separation from the leader and from one another may necessitate the distribution of leadership functions. Additionally, Misiolek and Heckman (2005) examined the patterns of emergent leadership in 
virtual teams, finding that distribution of leadership was more effective for these types of teams than traditional vertical leadership. Finally, in their study of virtual teams conducting social work projects, Pearce, Yoo, and Alavi (2004) found that shared leadership was a stronger predictor of team performance than vertical leadership. Therefore, while additional research is certainly needed, these initial findings illustrate the importance of understanding shared leadership in virtual environments.

\section{Virtuality and Distribution: Their Impact on Shared Leadership}

In order to provide a stronger foundation for understanding shared leadership in virtual teams, it is advantageous to draw from the current literature regarding leadership and leader functions. As mentioned previously, Morgeson et al., (2009) suggests that leadership originates from four sources, derived from two structural dimensions: locus of leadership (internal vs. external) and formality of leadership (formal vs. informal). Further, Morgeson et al., (2009) address the effectiveness of specific leadership functions deriving from each of the four sources under the overarching assumption that team work occurs in cycles. This is a prominent theme in the teams literature, as team work as been conceptualized as 'recurring cycles of mutually dependent interaction' (Morgeson et al., 2009, p. 5). To build on this, Morgeson and colleagues focus on the temporal cycles (phases) proposed by Marks, Mathieu, and Zaccaro (2001). Specifically, they concentrate on the transition phase, when evaluation and planning processes occur that foster the possibility of the team's goal attainment, and action phase, when work performed is directly tied to the team's goal. Morgeson and colleagues break down leadership functions that should occur within each phase and address the effectiveness of each function relative to its originating source. Furthermore, they draw upon the extensive body of leadership literature to conceptualize what leadership sources are best for each type of leader function, based on whether the source is external or internal to the team, as well as informal or formal. For example, for training team members, Morgeson and colleagues suggest that if this function originates from an external-informal source, it will be more effective than if it originated from an internal-informal source.

Though the notion of shared leadership is encapsulated within the internal-informal source, the implications of how these leadership functions will act under the virtual and distributed circumstances are not addressed. Subsequently, the remainder of this paper will provide a more detailed exploration of the impact of virtuality and distribution on leadership functions as described by Morgeson et al., (2009). Specifically, we theoretically explore the effectiveness of sharing lead- ership functions under the virtuality/distribution framework proposed earlier. To do so, we address and define leader functions occurring in the transition phase (e.g., compose team, define mission, establish expectations and goals) and action phases (e.g., monitor team, manage team boundaries, challenge team, perform team task) of team performance that are identified by Morgeson and colleagues as being performed most successfully through internal-informal sources (i.e., shared leadership). For each of these leader functions, we will provide propositions regarding how virtuality and distribution may impact the degree to which these leader behaviors may be shared, how varying degrees of both virtuality and distribution may hinder or promote their functionality when such leader behaviors are shared, as well as any potential mechanisms which may reduce any negative impacts that virtuality and distribution may have on these leader functions when they are shared. This is not meant to be an allencompassing list of propositions that examines every potential interaction of shared leadership, virtuality, and distribution, but instead serves to provide direction regarding the types of issues in need of future exploration.

\section{Transition Phase}

The idea that teams function in cycles of performance episodes is an integral aspect in the emergence of shared leadership. During the transition phase, teams largely focus on assessing and structuring group composition, defining team goals and objectives, planning how to accomplish these goals, and evaluating and providing feedback from previous performance episodes. This phase allows for leader behaviors related to the structuring, planning, evaluating, and feedback of team processes to occur. Even though these processes have been hypothesized to be more difficult for distributed and virtual teams (Blackburn, Furst, \& Rosen, 2003), the processes are, nonetheless, crucial for distributed and virtual team performance (Lurey \& Raisinghani, 2001). Empirical research focusing on virtual teams has been inconclusive regarding processes occurring in the transition phase (Martins, Gilson, \& Maynard, 2004). As such, we examine several shared leader functions and how levels of virtuality and distribution may impact them.

Define Mission. An integral part of any team process is the presence of a clear, concise, and direct mission. How the mission gets defined is largely the part of the team leader. The outcome of this leader function is to break down the ultimate goal of the team into tangible, achievable, challenging tasks and assure that these tasks are shared among team members. The more ambiguous and monotonous the tasks are, the less motivated team members will be in achieving those tasks and the less likely team members will have a shared understanding 
of the tasks. Without a shared understanding of the mission, team members will be less likely to develop the collaborative and cohesive relationships necessary for effective team functioning (Barry, 1991 as cited in Morgeson et al., 2009). However, research has shown that informal leaders, like those found in virtual and distributed teams, engage in more mission development and planning behaviors than formal leaders (Pielstick, 2000) and that teams with shared leadership do not differ from teams with hierarchical leadership structures in their mission development processes (Carte, Chidambaram \& Becker, 2006).

These results, however, may not necessarily hold true across different types of virtuality and distribution. Highly virtual may might not necessarily be able clearly define their mission as well as teams with low virtuality because of the lack of audio and visual cues. This can impact shared leadership, as it takes away from the flow of information needed to ensure a shared understanding of mission, which is critical when multiple leaders are attempting to coordinate in defining the mission. Therefore, we propose:

Proposition la. Highly virtual teams who share the function of defining the mission among individuals will have more difficulty defining the mission than teams low in virtuality.

However, it is also possible that virtual teams that have a moderate degree of virtuality may be more cognizant of the fact that they are not able to access these social cues and therefore attempt to compensate in other ways, reducing the negative impact of virtuality. Indeed, Mesmer-Magnus and colleagues (2009) found in their meta-analysis of virtual teams and information sharing that virtual teams with a moderate degree of virtuality were more likely to share information and therefore perform better than either high or low virtuality teams. In terms of mission definition, this could mean that team members sharing this function would attempt to maximize their degree of virtuality to ensure clarity of the mission, such as through using multiple virtual tools (e.g., text, telephone conversations) to convey information. Therefore we propose:

Proposition $1 b$. Virtual teams with a moderate degree of virtuality who share the function of defining the mission will have less difficulty defining the mission than high virtuality teams.

Additionally, the distribution of the team could impact the use of shared leadership to establish a shared understanding of the team's mission. Teams that are not fully distributed may be more prone to defining and structuring the team's mission specific to their team cell. For example, even if each team cell's understanding of the mission is the same within the cell, there may be differences across cells that prevent appropriate coordination and communication. This may be more pronounced if the leaders sharing the function of mission definition are all collocated, as they may be less likely to perceive differences in shared understanding without the physical presence of members. However, if fully distributed, the shared leaders may make additional efforts to ensure that all team members understand the mission. These different perceptions of the mission could lead to poor execution of behaviors in the action phase and, subsequently, poorer performance. Therefore, it is proposed:

Proposition 1c. Mission definition will be more challenging in partially distributed teams than in fully distributed teams, particularly when leaders sharing the function of mission definition are collocated.

However, there are proposed benefits of virtuality and distribution. With high virtuality, teams externalize information electronically, allowing information to be captured as a more permanent record that can later be reviewed, either by members or leaders, to ensure shared understanding (Malhotra, Majchrzak, \& Rosen, 2007). This externalization of knowledge allows teams to clearly share information, allowing for a more discernable set of mission tasks (Alge, et al., 2003). Therefore, it may be the case that when leaders sharing the mission definition function utilize virtual tools effectively as resources for storing and retrieving information, they will be better able to establish the mission. Thus, we propose:

Proposition 1d. Virtual teams whose leaders maximize the capabilities of virtual tools will be more successful in defining the mission than those who do not.

Establish Expectations and Goals. Once a team has a common grasp on the mission, the next leadership function involves establishing performance expectations and goals relative to that mission. In shared leadership contexts, this function is often served by multiple members of the team, with individual team members typically conveying their own expectations while adhering to a common set of goals and expectations emerging from team interaction (Pearce \& Sims, 2002). Regardless of the leadership source, teams that facilitate goal setting are associated with improved performance (Cohen, Chang, \& Ledford, 1997). In the virtual team context, the presence of expectations and goals has been shown to help develop a common team identity, which was subsequently associated with team members collaborating more effectively (Cramton, 2001; Javenpaa \& Leidner, 1999). However, no empirical research has investigated the aspects of shared leadership that impact the emergence of such shared expectations in virtual teams.

In terms of the impact of virtuality and distribution on sharing the function of setting expectations and 
goals, it is likely that both the degree of distribution and virtuality may interact to negatively impact expectations and goals. As with defining the mission, distributing team members across time and space, along with reducing the richness of their communication media, can negatively impact how well information is shared (Cramton, 2001; Burke, et al., 2005). Furthermore, as team members in highly virtual and fully distributed teams may be from different cultures, it is likely that developing a shared understanding regarding the expectations of the team will be more challenging, as culturally driven expectations may be distorted through misunderstandings or biases (Jarvenpaa, Knoll, \& Leidner, 1998; Kayworth \& Leidner, 2001/2002). This team member diversity can be especially difficult when the establishment of expectations and goals is shared across team members who have differing cultural beliefs as well. Therefore, we propose:

Proposition 2a: Expectations and goals will be more challenging to establish in highly virtual and fully distributed teams than teams moderate or low in virtuality and distribution.

Potentially playing a key role in the development of common expectations when leadership is shared is the degree to which routines are present in virtual teams. Bell and Kozwloski (2002) propose that leaders of virtual teams should develop appropriate habitual routines early in the team's lifecycle, which will aid in perpetuating patterns of behavior. Habitual routines aid in establishing expectations and reducing uninhibited individual behavior, which can be problematic in virtual teams (Siegel, Dubrovsky, Kiesler, \& McGuire, 1986; Straus \& McGrath, 1994). Establishing habitual routines may be especially beneficial when leadership is shared, as it provides some standards as to which members will be serving particular leader functions, and how these leader functions may be shared amongst multiple or single members at any given time (Hambley, et al., 2007). Therefore, we propose:

Proposition 2: Shared leadership will be more effective in establishing expectations and goals in virtual teams when habitual routines are present early in the team's lifecycle.

Structure and Plan. Up to this point, these leader functions have established how team members will work independently from one another. The structuring and planning function addresses the potential interactions between team members during the transition phase. Team members need to develop a shared understanding of how they will coordinate their actions effectively in the accomplishment of team goals. Moregson et al. (2009) informally suggest three main parts to the structuring and planning function of lead- ership: method, role clarification, and timing. Method describes how work will be accomplished, role clarification depicts who will do the work, and timing taps when work will get done. In shared leadership, members of the team are involved in the day-to-day functions. Intuitively, by sharing this responsibility, members should be more effective in understanding what it the best way to the work, the temporal demands of the task, team member expertise, and how to utilize team member availability and expertise to meet temporally driven task demands.

As this leadership function depends on the team members' understanding, the virtuality and distribution of the team are bound to impact the effectiveness of this function, specifically in terms of the formality of interactions required. While structuring and planning may be vulnerable to similar issues as mentioned for defining the mission and setting goals and expectations, it is also possible that there can be some ways in which virtuality and distribution can be advantageous for this leader function. Specifically, low virtuality has the potential to hinder the effectiveness of this leadership function by providing fewer opportunities to clarify the structure and plans in dynamic contexts. For example, it may take more effort for low virtuality, face to face teams to initiate planning and structuring, as they require face to face meetings to do so. When considering partially distributed teams, if the interactions between team cells occur in a more formal matter, both teleconferences and videoconferences must be planned in advance, which can be challenging if this involves members in different time zones or countries (Solomon, 1995). This, however, is not a restriction of high virtuality teams, as regardless of synchronicity information can be passed back and forth through more informal channels such as instant messaging or email as needed to supplement face to face meetings. Indeed, this type of back and forth communication can enhance structuring and planning, especially when tasks require reciprocal interdependence and leaders as spread across distance (Bell \& Kozlwoski, 2002). Therefore, we propose:

Proposition 3: Shared leadership of highly virtual and partially/fully distributed teams that utilize more informal virtual tools (e.g., instant messaging, emails) on a regular basis will be more effective at structuring and planning than if using more formal means (e.g., teleconferencing, videoconferencing) that require additional coordination.

Provide Feedback. An important step in adapting planning and performance in subsequent performance cycles is the distribution of effective feedback. This leadership function allows teams to understand previous performance cycles, adapt future behavior based on previous performance, and develop over time (Einstein \& Humphreys, 2001). Within the context of 
shared leadership, Morgeson et al., (2009) suggest that informal internal leadership is best at providing and receiving ongoing task-related feedback, however, other sources are better at providing feedback concerning environmental changes and reflection of progress towards team goals. However, there has been some empirical research suggesting that when virtual team leaders provide evaluative and systematic feedback, there is a greater degree of team identification and commitment (Sivunen, 2006).

The effectiveness of this leadership function, however, is highly dependent of the ease and type of information conveyed between team members. For example, teams with low virtuality are able to communicate different types of information with greater ease than medium virtuality teams (e.g., images). Highly virtual teams could potentially share complex feedback (e.g., images, lists, bulleted points) with one another at the same level as low virtuality teams due to the use of technologies such as videoconferencing and collaborative software (Kirkman \& Mathieu, 2005); however, because of the social limits of these communication mechanisms, low virtuality teams might have an easier time with expressing this content in socially appropriate ways. This is one area in which shared leadership may have a distinct advantage for virtual and distribute teams, if the leaders providing feedback are distributed across locations. For example, teams with multiple members will have an easier time providing feedback within collocated subsets of the team because they are communicating face to face. However, the ease of providing feedback decreases when this leadership function travels across locations. Therefore, we propose:

Proposition 4: Distribution of leaders sharing the function of providing feedback impacts the success of this feedback, such that feedback will be more successful when members sharing this function are spread across locations than when all members sharing the function are collocated.

\section{Action Phase Leadership Functions}

When team members are focused on activities that are directly contributing to their goals, they are said to be in the action phase (Marks, et al., 2001). According to Morgeson et al., (2009) there is another set of leader functions performed in this phase. The functions performed in this phase can be more time sensitive than those functions performed in the transition phase due to the interactivity needed to perform these functions. We will look at the following leadership functions through the lens of shared leadership under different levels of virtuality and distribution: monitor team, perform team task, solve problems, support social climate.

Monitor Team. In order to keep a team on track and fulfilling its potential, a leadership function that must be performed is the monitoring of the team. This function is not limited to only monitoring team members' processes and performance, but also extends to monitoring the environment (Hackman \& Walton, 1986; McGrath, 1962; Tukl, 1989). Team monitoring provides critical information to team members that influence the impact of subsequent leadership functions. When team monitoring is present, team leaders are seen as more effective and the team is more cohesive (Kane, Zaccaro, Tremble, \& Masuda, 2002). However, Morgeson et al., (2009) suggest that different sources are better able to provide specific types of monitoring than others. It is suggested that when this leadership function occurs as function of shared leadership, the monitoring behaviors performed are likely to focus on internal team aspects (e.g., performance, processes), while external leadership will focus on team environment monitoring.

In both virtual and distributed teams, the ability to monitor some or all of these behaviors may become more challenging, especially in early stages of team development. Particularly, as distribution increases, it is more difficult for leaders to detect problems among team members until the issue may already be out of hand (Shuffler \& Goodwin, 2007). Furthermore, it is likely that highly virtual teams' leaders will have a harder time gauging the level of functioning in a team than teams that have low virtuality due to the lack of verbal and non-verbal cues (Owens, Neale, \& Sutton, 2000). Additionally, unevenly and evenly distributed teams may be able to monitor within cell processes more effectively but experience the challenges with detecting differences in processes and performance among cells. However, all of this may be a function of time, as time has been found to be a key factor in virtual team performance (Martins et al., 2004). One notable finding in the virtual teams literature is that such teams often perform on the same level as-or better than-face to face teams if given enough time to establish patterns and an understanding of how members function (Jarvenpaa \& Leidner, 1999). This may be especially true when monitoring is shared among team members, as team members may need additional time to determine which members are monitoring other members and for partially distributed teams, establish mechanisms for developing monitoring both within and across teams. Therefore, we propose that:

Proposition 5: The effectiveness of shared team monitoring is a function of time in virtual teams, such that virtual teams with a compressed amount of time to establish a pattern or mechanism for monitoring will be less effective than virtual teams with more time.

Perform Team Task. The functional leadership approach suggests that it is the team leader's role to fulfill any necessary tasks/duties that other team mem- 
bers cannot (Fleishman, et al., 1991; Zaccaro, Heinen, $\&$ Shuffler, 2009). This theory is seen within this leadership function and is especially important to shared leadership. Leaders who are involved in day-to-day activities have a better understanding of the team process and where the team may be lacking in terms of task completion. This ground level understanding provides leaders with "the ability to get things done" (Hackman and Walton, 1986, pp. 108), which is necessary in order to perform this task. Mumford and colleagues (Mumford, Campion, \& Morgeson, 2006; Mumford, Van Iddekinge, Morgeson, \& Campion, 2008) hypothesize several leadership roles: contactor, creator, contributor, completer, and critic. Due to the nature of shared leadership, it is likely that the division of these roles among members instead of simply having one leader perform all these roles may be a great advantage as it spreads the cognitive load of these roles across multiple people. Thus we propose:

Proposition 6a: Virtual teams who more equally distribute various leadership roles (e.g., creator, contributor, completer) will be more successful at performing the team task than those who do not.

However, this may not always hold when considering the team's degree of virtuality and distribution. Virtual teams tend to have a focus on task-specific issues and less of a focus on relation-specific issues (Chidambaram \& Bostrom, 1997; Walther, 1996). Therefore, it may be likely that these types of roles are less successful in virtual teams, as they simply may not get the attention they need even when roles are divided among team members. Furthermore, it may be more difficult in highly virtual and more distributed environments for leaders to determine when to enact their leadership roles, as it may be more difficult to detect when the team needs assistance. This can be a particular problem, as Klein et al (2006) found that in shared leadership work environments, teams that were more effective had leaders that were able to recognize when it was necessary to either delegate responsibilities or directly intervene to maintain high levels of performance. As virtuality and distribution increase, it may be more challenging for leaders sharing this responsibility to recognize when to intervene or delegate, especially in terms of relation specific issues. This may be especially problematic in partially distributed teams where one or more individuals are distributed from those sharing the leadership function, as their needs may be especially difficult to assess. Thus we propose:

Proposition 6b: As the degrees of virtuality and distribution increase in teams, leaders sharing the function of taking an active role in the team's task will be less successful, particularly in terms of assisting in relation-specific issues.
Solve Problems. A team facing complex and ambiguous situations is not an uncommon occurrence in modern day organizations. It is a leadership responsibility to simplify and clarify these team dilemmas. Accordingly, a better understanding of the day-to-day activities, along with the first hand knowledge of team members, makes shared leadership an optimal condition for this function to operate within. Problem solving typically involves identifying and evaluating problems with the task, effectively using team expertise to address problems, and, lastly, providing effective solutions to problems (Hiller, Day, \& Vance, 2006). Teams sharing the leadership function are in the best position of any type of leadership to address problems that arise in the team, due to their proximity to the issue (Morgeson, et al., 2009).

In terms of virtual teams enacting shared leadership, the impact of the virtuality and distribution of the team could potentially interact with the type of problem occurring, causing team members to be either more proximal or distal from the problem occurring. For example, low virtual team could better address scenarios where the problem can be solved via verbal and nonverbal behaviors (e.g., talking through the process of a complicated procedure), while teams that are highly virtual will only be able to provide the steps to that procedure without associated social cues, which could be less effective. However, in teams that are highly virtual and sharing this leadership function, if the problem requires creativity to solve it, having more team members available as well as a combination of virtual tools to be utilized may provide a better solution to the problem (Kayworth \& Leidner, 1999). Thus we propose:

Proposition 7a: Success of leaders who share problem solving responsibilities in virtual teams will depend upon the degree of virtuality as well as the type of problem to be solved.

Furthermore, the distribution of the team may also matter. When receiving shared input on how to solve a problem, unevenly distributed cells (in terms of either members or importance of information shared) may encourage the development of majority/minority differences, introducing unnecessary conflict (MontoyaWeiss, et al., 1999). Thus, it is proposed:

Proposition 7b: In partially distributed virtual teams, sharing of problem solving functions will be more challenging when teams are unevenly distributed.

Support Social Climate. Finally, an integral part of the success of shared virtual team leadership is a cohesive team (Powell, Piccoli, \& Ives, 2004), therefore, the leadership function of supporting social climate is critical to these team's effectiveness. This function typ- 
ically addresses interpersonal issues within the teams, which might be more likely to occurred in shared leadership teams if there is a disconnect between team member's perceptions of teams roles, expertise, and the like. However, leaders within shared leadership teams are more apt to address this issue due their proximity with the members involved. Some of the behaviors associated with this leadership function include respect for team member's idea, warmth, and concern for interpersonal discrepancies (Schminke, Wells, Peyrefitte \& Sebora, 2002). Though shared leadership should facilitate this leadership function, very little empirical research has investigated this issue directly.

A potential roadblock of this leadership function could be the degree to which team members interact virtually. It could be theorized that, in order to fully understand climate, one needs to assess the verbal and non-verbal social cues occurring within a team (Kayworth \& Leidner, 2001/2002; Connaughton \& Shuffler, 2007). However, as the level of virtuality increases, team members are less likely to come to a shared understanding of the team's social climate. This inconsistency in team member's understanding of social climate, should be especially apparent in fully distributed teams. Thus, we propose:

Proposition 8a: Shared leadership will be more effective in maintaining the social climate of virtual teams than traditional vertical leadership.

Proposition 8b: The success of shared leadership in maintain the social climate of virtual teams will be impacted by the degree of virtuality and distribution, such that shared leaders in highly virtual and fully distributed teams will be less successful in maintaining social climate than moderate or low virtuality, partially distributed or face-to-face teams.

\section{Conclusion \& Future Directions}

Certainly, there are many areas of research to be explored when considering shared leadership in virtual teams. As mentioned previously, this set of propositions is not meant to serve as a comprehensive list of the needs for future research, but instead is designed to provide insight into the types of questions that need to be explored in this area of leadership and teams research. In terms of future research, each of these propositions is in need of empirical support, whether it be through qualitative or quantitative means.

Researchers should consider a range of methods to explore this area of research, as much of the virtual teams literature has benefitted from the use of qualitative case studies and communication analyses to advance our understanding. Furthermore, from a quantitative perspective, techniques such as social network analysis can be advantageous in this type of research, as it provides a more holistic examination of the team as opposed to simply capturing self-report measures. It is also important that researchers consider utilizing different techniques for aggregating virtual teams and shared leadership data, as there may be much to gain from understanding how the minimum or maximum levels of, or variance within, a construct can affect teams differently than just examining the average level (Kozlowski \& Klein, 2000).

In addition to advancing theory, exploring virtuality, distribution, and shared leadership can greatly benefit practice as well. As mentioned earlier, virtual teams are continuing to increase in prevalence in the workplace; therefore, understanding how differing degrees of virtuality and distribution can impact the success of leadership is critical. One area in which advancing research regarding the aforementioned propositions may be particularly beneficial is the training of leaders and team members in virtual environments. Developing virtual team leaders is no easy feat, as noted in a range of practical guidelines already in existence (Avolio \& Kahai, 2003; Bell \& Kozlowski, 2002; Cascio \& Shurygailo, 2003). However, preparing leaders for virtual teams is even more challenging when considering how needs may differ based on the degree of virutality and distribution. Furthermore, virtual teams may combine members with varying degrees of leader expertise, with little to no preparation regarding how to combine this expertise to address the multiple leader functions. Therefore, from a practical perspective, providing clarity on many of the propositions provided here can aid in determining the specific content of training programs geared towards improving leadership in virtual teams. By focusing on the differences among degrees of virtuality and distribution that may impact the success of leader functions in such teams, training programs can be developed that specifically target the needs of a particular organization or type of virtual team (e.g., high distribution, moderate virtuality). Furthermore, shared leadership training programs can also substantial implications for developing effective virtual team leadership, as they can promote not the singular "leader" development that many organizations currently favor, but a more team-based approach that improves "leadership" as a whole across the team.

Another area with practical implications for understanding shared leadership in virtual teams is the selection and composition of such teams. Certainly, some individuals may be more prepared than others to work in virtual teams (Blackburn, et al., 2003); however, it may also be possible that the degree of virtuality and distribution matters when considering virtual team composition, as some individuals may be better able to adapt to more or less virtual and distributed environments. A team member who is able to work effectively on a fully distributed and highly virtual team may find face to face meetings very challenging in terms of 
accomplishing tasks. When adding in the fact that leadership functions may be shared across team members, identifying members for virtual teams becomes not simply a factor of which individuals' specific taskrelevant skills are necessary for successful performance, but also their skill in performing necessary leader functions. Therefore, investigating the research propositions within this paper, as well as others that connect these different factors, is critical to advancing our understanding of team member selection and team composition as a whole.

In summary, the goal of this paper is to inspire future thinking regarding the roles of virtuality, distribution, and their impact on shared leadership functions in virtual teams. By providing a clear cut set of definitions as well as propositions to drive research, it is hoped that researchers will be better prepared to address the needs of both theory development and practitioners. While shared leadership has little empirical research in terms of virtual teams, its increasing prevalence in the workplace and around the world demands attention.

\section{References}

Alge, B. J., Wiethoff, C., \& Klein, H. J. (2003). When does the medium matter? Knowledge-building experiences and opportunities in decision-making teams. Organizational Behavior and Human Decision Processes, 91, 26-37.

Avolio, B. J., \& Kahai, S. S. (2003). Adding the "E" to ELeadership: How it May Impact Your Leadership. [Article]. Organizational Dynamics, 31(4), 325-338.

Bass, B. M. (1990). Bass and Stodgill's handbook of leadership: Theory, research, and management applications ( $3^{\text {rd }}$ ed). New York: Free Press.

Bell, B. S., \& Kozlowski, S. W. J. (2002). A typology of virtual teams: Implications for effective leadership. Group \& Organization Management, 27, 14-49.

Blackburn, R., Furst, S. A., \& Rosen, B. 2003. Building a winning virtual team: KSA's, selections, training, and evaluation. In C. B. Gibson \& S. G. Cohen (Eds.), Virtual teams that work: Creating conditions for virtual team effectiveness. San Francisco: Jossey-Bass

Bos, N., Olson, J. S., Nan, N., Shami, N. S., Hoch, S., and Johnston, E.. 'Collocation Blindness' in Partially Distributed Groups: Is There a Downside to Being Collocated? In Proc. CHI 2006.

Boudreau, M. C., Loch, K. D., Robey, D., \& Straud, D. (1998). Going global: Using information technology to advance the competitiveness of the virtual transnational organization. Academy of Management Executive, 12, 120-128.

Burke, S., Hess, K. P., Priest, H. A., Rosen, M., Salas, E., Paley, M., \& Riedel, S. (2005). Facilitating leadership in a global community: A training tool for multicultural team leaders. Proceedings of the Interservice/Industry
Training, Education, \& Simulation Conference (I/ITSEC). Orlando, FL.

Burke, C. S., Lum, H. C., Scielzo, S. A, Smith-Jentsch, K., \& Salas, E. (2008). Examining measures of team cognition in virtual teams: A heuristic and guidelines. D. Schmorrow, J. Cohn, \& D. Nicholson (Eds). The Handbook of Virtual Environment Training. (1), 266-283.

Cascio, W. F., \& Shurygailo, S. (2003). E-Leadership and virtual teams. Organizational Dynamics, 31, 362-376. doi: 10.1016/s0090-2616(02)00130-4

Carson, J. B., Tesluk, P. E., \& Marrone, J. A. (2007). Shared leadership in teams: An investigation of antecedent conditions and performance. Academy of Management Journal, 50, 1217-1234.

Carte, T. A., Chidambaram, L., \& Becker, A. (2006). Emergent leadership in self-managed virtual teams: A longitudinal study of concentrated and shared leadership behaviors. Group Decision and Negotiation, 15, 323-343.

Chidambaram, L. \& Bostrom, R. (1997). Group development (II): Implications for GSS research and practice. Group Decision and Negotiation, 6, 231-254.

Chudoba, K. M., Wynn, E., Lu, M., \& Watson-Manheim, M. B. (2005). How virtual are we? Measuring virtuality and understanding its impact on a global organization. Information Systems Journal, 15, 279-306.

Cohen S. G., Chang L., \& Ledford G. E. (1997). A hierarchical construct of self-management leadership and its relationship to quality of work life and perceived work group effectivenes. Personnel Psychology, 50, 275-308.

Cohen, S. G., \& Gibson, C. B. (2003). In the beginning: Introduction and framework. In C. B. Gibson \& S. G. Cohen (Eds), Virtual teams that work: Creating conditions for team effectiveness (pp. 1-13). San Francisco, CA: Jossey-Bass.

Cogburn, D. L., \& Levinson, N. S. (2003). U.S.-Africa virtual collaboration in globalization studies: Success factors for complex, cross-national learning teams. International Studies Perspectives, 4, 31-54.

Connaughton, M. L., \& Shuffler, M. (2007). Multinational and multicultural distributed teams. Small Group Research, 38, 387-412.

Cramton, C. D. (2001). The mutual knowledge problem and its consequences for dispersed collaboration. Organization Science, 12, 346-371. doi:10.1287/orsc.12.3.346. 10098

Cramton, C. D. (2003). Finding common ground in dispersed collaboration. Organizational Dynamics, 30, 356367.

Cummings, J. N. and Kiesler, S. (2008). Who collaborates successfully? Prior experience reduces collaboration barriers in distributed interdisciplinary research. Proc. Of CSCW'08, ACM press, November 8-12 (2008) San Diego, CA, USA.

Daft, R. L., \& Lengel, R. H. (1984). Information richness: A new approach to managerial behavior and organizational design. Research in Organizational Behavior, 6, 191-233.

Day, D. V., Gronn, P., \& Salas, E. 2004. Leadership capacity in teams. Leadership Quarterly, 15, 857-880. 
Duarte, D. L., \& Snyder, N. T. (2006) Mastering Virtual Teams: Strategies, tools, and techniques that succeed. San Francisco, CA: Jossey-Bass.

Earley, P. C., \& Mosakowski, E. (2000). Creating hybrid cultures: An empirical test of transnational team functioning. Academy of Management Journal, 43, 26-49.

Einstein, W. Q. \& Humphreys, J. H. (2001). Transforming leadership: Matching diagnostics to leader behaviors. Journal of Leadership and Organizational Studies, 8, 4860.

Ensley, M. D., Hmieleski, K. M., \& Pearce, C. L. (2006). The importance of vertical and shared leadership within new venture top management teams: Implications for the performance of startups. Leadership Quarterly, 17, 217231. doi: 10.1016/j.leaqua.2006.02.002

Fiore, S. M., Salas, E., Cuevas, H. M., \& Bowers, C. A. (2003). Distributed coordination space: toward a theory of distributed team process and performance. Theoretical Issues in Ergonomics Science, 4, 340.

Fleishman, E. A., Mumford, M. D., Zaccaro, S. J., \& Levin, K. Y. (1991). Taxonomic efforts in the description of leader behavior: A synthesis and functional interpretation. Leadership Quarterly, 2, 245-287.

Friedrich, T. L., Vessey, W. B., Schuelke, M. J., Ruark, G. A., \& Mumford, M. D. (2009). A framework for understanding collective leadership: The selective utilization of leader and team expertise within networks. Leadership Quarterly, 20, 933-958. doi: 10.1016/ j.leaqua.2009.09. 008

Gibb, C. A. (1951). An experimental approach to the study of leadership. Occupational Psychology, 25, 233-248.

Gibson, C. B., \& Gibbs, J. L. (2006). Unpacking the concept of virtuality: The effects of geographic dispersion, electronic dependence, dynamic structure, and national diversity on team innovation. Administrative Science Quarterly, 51, 451- 495.

Hackman, J. R. \& Walton, R. E. (1986). Leading groups in organizations. In P. S. Goodman (Ed.), Designing effective work groups (pp. 72-119). San Francisco: Jossey-Bass.

Hambley, L. A., O’Neill, T. A., \& Kline, T. J. B. (2007). Virtual team leadership: Perspectives from the field. International Journal of e-collaboration, 3, 40-64. doi: 10.1016/j.obhdp.2006.09.004

Hertel, G., Geister, S., \& Konradt, U. (2005). Managing virtual teams: A review of current empirical research. Human Resource Management Review, 15, 69-95. doi: 10.1016/j.hrmr.2005.01.002

Hiller, N. J., Day, D. V., \& Vance, R. J. 2006. Collective enactment of leadership roles and team effectiveness: A field study. Leadership Quarterly, 17: 387-397.

Hinds, P. J., \& Bailey, D. E. (2003). Out of sight, out of sync: Understanding conflict in distributed teams. Organization Science, 14, 615-632.

Hinds, P. J., \& Mortensen, M. (2005). Understanding conflict in geographically distributed teams: The moderating effects of shared identity, shared context, and spontaneous communication. Organization Science, 16, 290-307.

House, R. J., \& Toronto, U. (1976). A 1976 Theory of
Charismatic Leadership. Working Paper Series 76-06.

Huang, H. and Ocker, R. (2006). Preliminary insights into in-group/out-group effect in partially distributed teams: a analysis of participant reflection. In the Proceedings of SIGMIS-CPR'06, April 13-15, Claremont, CA, pp. 264272. New York: The ACM Press.

Jarvenpaa, S. L., \& Leidner, D. E. (1999). Communication and trust in global virtual teams. Organization Science, 10, 791-815.

Jarvenpaa, S. L., Knoll, K., \& Leidner, D. E. (1998). Is anybody out there? Antecedents of trust in global virtual teams. Journal of Management Information Systems, 14, 29-64.

Jackson, M.C. (2000) Systems Approaches to Management. New York: Kluwer.

Kane, T. D., Zaccaro, S. J., Tremble, T. R., \& Masuda, A. D. (2002). An examination of the leader's regulation of groups. Small Group Research, 33, 65-120.

Kayworth, T. R. \& Leidner, D. E. (2001/2002). Leadership effectiveness in global virtual teams. Journal of Management Information Systems, 18, 7-40.

Kiesler, S., \& Cummings, (2002). What do we know about proximity and distance in work groups? A legacy of research. In P. Hinds \& S. Kiesler (Eds), Distributed work (pp. 57-80). Cambridge, MA: MIT Press.

Kirkman, B., \& Mathieu, J. (2005). The dimensions and antecedents of team virtuality. Journal of Management, 31, 700-718.

Klein, K. J., Ziegert, J. C., Knight, A. P., \& Xiao, Y. (2006). Dynamic delegation: Shared, hierarchical, and deindividualized leadership in extreme action teams. Administrative Science Quarterly, 51, 590-621.

Kock, N. (2002), Evolution and media naturalness: A look at e-communication through a Darwinian theoretical lens. In L. Applegate, R. Galliers, \& J. L. DeGross (Eds.), Proceedings of the 23rd International Conference on Information Systems (pp. 373-382). Atlanta, GA: The Association for Information Systems.

Kock, N. (2004). The Psychobiological Model: Towards a New Theory of Computer-Mediated Communication Based on Darwinian Evolution. Organization Science, 15, 327-348. doi: 10.1287/orsc.1040.0071

Kock, N., \& Hantula, D. (2005). Do we have e-collaborative genes? International Journal of e-Collaboration, 1, i-ix.

Komaki, J. L., Desselles, M. L., \& Bowman, E. D. (1989). Definitely not a breeze: Extending an operant model of effective supervision to teams. Journal of Applied Psychology, 74, 522-529. doi: 10.1037/00219010.74.3. 522

Kozlowski, S. W. J. \& Klein, K. J. (2000). A multilevel approach to theory and research in organizations: Contextual, temporal, and emergent processes. In K. J. Klein \& S. W. J. Kozlowski (Eds.), Multilevel theory, research, and methods in organizations: Foundations, extensions, and new directions (pp. 3-90). San Francisco, CA: Jossey-Bass.

Lambert, L. (2002). A Framework for Shared Leadership. Educational Leadership, 59, 37-41. 
Lurey, J. S. \& Raisinghani, M. S. (2001). An empirical study of best practices in virtual teams. Information and Management, 38, 523-544.

Lyons, R., Priest, H. A., Wildman, J. L., Salas, E., \& Carnegie, D. (2009). Managing Virtual Teams: Strategies for Team Leaders. Ergonomics in Design, 17, 8-13.

Malhotra A., Majchrzak A., \& Rosen B. (2007). Leading virtual teams. Academy of Management Perspecives. 21, 60-70.

Marks M. A., Mathieu J., \& Zaccaro S. J. (2001). A temporally based framework and taxonomy of team processes. Academy of Management Review, 26, 356-376.

Martins, L. L., Gilson, L. L., \& Maynard, M. T. (2004). Virtual teams: What do we know and where do we go from here. Journal of Management, 30, 805-836.

Maruping, L. M., \& Agarwal, R. (2004). Managing team interpersonal processes through technology: A task-technology fit perspective. Journal of Applied Psychology, 89, 975-990.

Maznevski, M. L., \& Chudoba, K. M. (2000). Bridging space over time: Global virtual team dynamics. Organization Science, 11, 473-492.

McGrath, J. E. (1962). Leadership behavior: Some requirements for leadership training. Washington, DC: U. S. Civil Service Commission, Office of Career Development.

Merkens, B. J., \& Spencer, J. S. (1998). A successful and necessary evolution to shared leadership: a hospital's story. International Journal of Health Care Quality Assurance, 11, i-iv.

Mesmer-Magnus, J. R. \& DeChurch, L. A. (2009). Information sharing and team performance: A metaanalysis. Journal of Applied Psychology, 94, 535-546.

Misiolek, N., \& Heckman, R. (2005). Patterns of emergent leadership in virtual teams. Paper presented at the 38th Hawaii International Conference on System Sciences.

Montoya-Weiss, M. M., Massey, A. P., \& Song, M. (2001). Getting it together: Temporal coordination and conflict management in global virtual teams. Academy of Management Journal, 44, 1251-1262.

Morgeson, F. P., DeRue, D. S., \& Karam, E. P. (2009). Leadership in teams: A functional approach to understanding leadership structures and processes. Journal of Management, 36, 1-39.

Morris, S. (2008). How to get real results from virtual teams. Human Resource Management International Digest, 16, 33-35.

Mortensen, M., \& Hinds, P. J. (2001). Conflict and shared identity in geographically distributed teams. International Journal of Conflict Management, 12, 212-238.

Mumford, T. V., Campion, M. A., \& Morgeson, F. P. (2006). Situational judgment in work teams: A team role typology. In J. A. Weekley \& R. E. Ployhart (Eds.), Situational judgment tests: Theory, measurement, and application (pp. 319-343). Mahwah, NJ: Erlbaum.

Mumford, T. V., Van Iddekinge, C. H., Morgeson, F. P., \& Campion, M. A. (2008). The team role test: Development and validation of a team role knowledge situational judgment test. Journal of Applied Psychology, 93, 250-267.
Murphy, L. R., Williams, E. S., McMurray, J., BaierManwell, L., Schwartz, M. D., Linzer, M., et al. (2007). III: Job and Organizational Design. In P. Carayon (Ed.), Handbook of human factors and ergonomics in health care and patient safety. (pp. 161-271). Mahwah, NJ US: Lawrence Erlbaum Associates Publishers.

Oakley J. G. (1998). Leadership processes in virtual teams and organizations. The Journal of Leadership Studies, 5, 3-17.

Ocker, R. J. (2008). The impact of personality on virtual team creativity and quality. In S. Kelsey \& K. St. Amant (Eds.), Handbook of research on computer mediated communication (Vols 1-2). (pp. 647-655). Hershey, PA US: Information Science Reference/IGI Global.

Oertig, M., \& Buegri, T. (2006). The challenges of managing cross-cultural virtual project teams. Team Performance Management, 12, 23-30.

Oetzel, J. G. (1998). Explaining individual communication processes in homogeneous and heterogeneous groups individualism-collectivism and self-construal. Human Communication Research, 25, 202-224.

O'Leary, M., \& Mortensen, M. (2005). Subgroups with attitude: Imbalance and isolation in geographically dispersed teams. Honolulu, HI: Academy of Management.

Owens, D. A., Neale, M. A., \& Sutton, R. I. (2000). Technologies of status management: Status dynamics in e-mail communications. Research on Managing Groups and Teams, 3, 205-230.

Paul, S., Samarah, I. M., Seetharaman, P., \& Myktyn, P. P. (2005). An empirical investigation of collaborative conflict management style in group support system-based global virtual teams. Journal of Management Information Systems, 21, 185-222.

Pearce, C. L. (2004). The future of leadership: Combining vertical and shared leadership to transform knowledge work. [Article]. Academy of Management Executive, 18, 47-57.

Pearce, C. L., \& Sims, H. P., Jr. (2000). Shared leadership: Toward a multi-level theory of leadership. Advances in the Interdisciplinary Studies of Work Teams, 7, 115-139.

Pearce, C. L., \& Sims, H. P. 2002. Vertical versus shared leadership as predictors of the effectiveness of change management teams: An examination of aversive, directive, transactional, transformational, and empowering leader behaviors. Group Dynamics: Theory, Research, and Practice, 6, 172-197.

Pearce, C. L., \& Conger, J. A. (2003). Shared leadership: Reframing the hows and whys of leadership. Thousand Oaks, CA: Sage.

Pearce, C. L., Yoo, Y., \& Alavi, M. (2004). Leadership, Social Work, and Virtual Teams: The Relative Influence of Vertical Versus Shared Leadership in the Nonprofit Sector. In R. E. Riggio \& S. S. Orr (Eds.), Improving leadership in nonprofit organizations. (pp. 180-203). San Francisco, CA US: Jossey-Bass.

Perry, M. L., Pearce, C. L., \& Sims Jr, H. P. (1999). Empowered Selling Teams: How Shared Leadership Can Contribute to Selling Team Outcomes. Journal of 
Personal Selling \& Sales Management, 19, 35-51.

Pielstick, C. D. (2000). Formal vs. informal learning: A comparative analysis. Journal of Leadership and Organizational Studies, 7, 99-114.

Polzer, J. T., Crisp, C. B., Jarvenpaa, S. L., \& Kim, J. W. (2006). Extending the faultline model to geographically dispersed teams: How colocated subgroups can impair group functioning. Academy of Management Journal, 49(4), 679-692.

Powell, A., Piccoli, G., \& Ives, B. (2004). Virtual teams: A review of current literature and directions for future research. ACM SIGMIS Database, 35, 6-36.

Rasters, G., G. Vissers, \& Dankbear, B. (2002). An inside look - Rich communication through lean media in a virtual research team. Small Group Research, 33, 718-734.

Sarker, S. (2005). Knowledge transfer and collaboration in distributed U.S.-Thai teams. Journal of Computer Mediated Communication, 10. Accessible at : doi:10.1111/j.1083-6101.2005.tb00278.x

Saunders, C., Van Slyke, C., \& Vogel, D.R. (2004). My time or yours? Managing time visions in global virtual teams. Academy of Management Executive, 18, 19-31.

Schminke, M., Wells, D., Peyrefitte, J., \& Sebora, T. C. (2002). Leadership and ethics in work groups. Group and Organization Management, 27, 272-293.

Siegel, J., Dubrovsky, V., Keisler, S., \& McGuire, T. W. (1986). Group processes in computer-mediated communication. Organizational Behavior and Human Decision Processes, 37, 157-187.

Sivunen, A. (2006). Strengthening identification with the team in virtual games: The leaders' perspective. Group Decision and Negotiation, 15, 345-366.

Solomon, C. M. (1995). Global teams: The ultimate collaboration. Personnel Journal, 74, 49-58.

Straus S.G. \& McGrath J. E. (1994). Does the medium matter? The interaction of task type and technology on group performance and members reactions. Journal of Applied Psychology, 79, 87-97.

Tannenbaum, R., \& Massarik, F. (1957). Leadership: A frame of reference. Management Science, 4(1), 1-19.

Ting-Toomey, S. (1999). Communicating across cultures. New York: Guilford.

Townsend, A. M., DeMarie, S. M., \& Hendrickson, A. R. (1998). Virtual teams: Technology and the workplace of the future. Academy of Management Executive, 12, 17-29.

Walther J. B. (1996). Group and interpersonal effects in international computer-mediated collaboration. Human Communication Research, 23, 342-369.

Webster, J., \& Wong, W. K. P. (2008). Comparing traditional and virtual group forms: Identity, communication and trust in naturally occurring project teams. The International Journal of Human Resource Management, $19,41-62$.

Workman, M. (2005). Virtual team culture and the amplification of team boundary permeability on team performance. Human Resource Development Quarterly, 16, 435458.

Wright, C. (2008). Reinventing human resource management: business partners, internal consultants and the limits to professionalization. Human Relations, 61, 10631086.

Yang, O., \& Shao, Y. E. (1996). Shared leadership in selfmanaged teams: A competing values approach. Total Quality Management, 7, 521-534. doi: 10.1080/ 09544129610621

Yeatts, D. E., \& Hyten, C. (1998). High-performing selfmanaged work teams: A comparison of theory to practice. Thousand Oaks, CA US: Sage Publications, Inc.

Yoo, Y., \& Alavi, M. (2004). Emergent leadership in virtual teams: what do emergent leaders do? Information \& Organization, 14, 27-58. doi: 10.1016/j.infoandorg.2003. 11.001

Yuan, Y. C., \& Gay, G. (2006). Homophily of network ties and bonding and briding social capital in computer-mediated distributed teams. Journal of Computer Mediated Communication, 11, 1062-1084.

Yukl, G.A. (1998). Leadership in Organizational, 4th edition, Englewood Cliffs, New Jersey.

Zaccaro, S. J., Heinen, B., \& Shuffler, M. 2009. Team leadership and team effectiveness. In E. Salas, G. F. Goodwin, \& C. S. Burke (Eds.), Team effectiveness in complex organizations: Cross-disciplinary perspectives and approaches: 83-111. New York: Routledge.

Zakaria, N.,Amelinckx, A., \& Wilemon, D. (2004). Working together apart? Building a knowledge-sharing culture for global virtual teams. Creativity and Innovation Management, 13, 15-29.

Manuscript Received: 26/02/2010

Revision Received: 08/03/2010 Accepted: 08/03/2010 